\title{
Epidemiologic survey of traumatic dental injuries in children seen at the Federal University of Rio de Janeiro, Brazil
}

\author{
Marina Alvine de Jesus ${ }^{(a)}$ \\ Lívia Azeredo A. Antunes(b) \\ Patrícia de Andrade Risso(c) \\ Marcos Vinícius Freire ${ }^{(\mathrm{d})}$ \\ Lucianne Cople Maia(e) \\ (a) MSc student; (b) MSc, Professor; ${ }^{(\mathbf{e})}$ Associate \\ Professor - Department of Pediatric \\ Dentistry and Orthodontics, School of \\ Dentistry, Federal University of Rio de \\ Janeiro, RJ, Brazil. \\ (c) Substitute Professor; (d)Associate Professor \\ - Discipline of Endodontics, School of \\ Dentistry, Federal University of Rio de \\ Janeiro, RJ, Brazil.
}

\begin{abstract}
This epidemiologic survey aimed at assessing the prevalence of traumatic dental injuries in children seen at the Federal University of Rio de Janeiro, Brazil. The records of a total of 111 children (aged 0 to 6 years) seen from 2004 to 2006 in the dental trauma clinic were surveyed, comprising a total of 201 traumatized primary teeth. Data pertaining to the child and to the trauma such as age, gender, etiology, teeth involved, type of traumatic injury, time elapsed between the trauma and seeking care, and the presence and kind of clinical and radiographic sequelae in the first visit were collected from the dental records. All variables studied were assessed by means of frequency analysis and the Chi-square test $(\mathrm{p}<0.05)$. A higher prevalence of trauma was observed in boys $(56.7 \%)$ and in the age group from $0-3$ years $(73.8 \%)$. The most affected teeth were the central incisors $(84.7 \%)$ and the most common trauma etiology was a fall from the child's own height $(63.0 \%)$. The supporting tissues were the most affected. Lateral luxation was the most frequent alteration observed $(33.4 \%)$, followed by concussion $(21.0 \%)$. Coronal discoloration $(17.7 \%)$ and external resorption $(18.3 \%)$ were, respectively, the most prevalent clinical and radiographic sequelae. Gender had no influence on the clinical $(\mathrm{p}=0.54)$ and radiographic $(\mathrm{p}=0.55)$ sequelae. Even though age had no influence on radiographic sequelae $(p=0.41)$, clinical sequelae were more prevalent in children aged 0 to 3 years $(\mathrm{p}=0.03)$. In conclusion, traumatisms in primary teeth were more prevalent in boys, and in 0-3-year-old children. Luxation was the most frequent traumatic lesion, and coronal discoloration and external resorption were the most prevalent sequelae.
\end{abstract}

Descriptors: Tooth injuries; Wounds and injuries; Child; Tooth, deciduous.

\section{Introduction}

Dental trauma is a very significant problem in the primary dentition. ${ }^{1}$ It has a physical, aesthetic and psychological impact, not only on the child but also on his/her parents. ${ }^{2}$

No agreement exists on the prevalence of traumatic dental injuries, as this has differed from study to study and from country to country. Studies report frequencies ranging from 10.2 to $69.2 \% .^{2,3,4,5,6}$

The most common age group in which primary tooth injury occurs is 1 to 3 years. ${ }^{7}$ Nonetheless, Osuji et al. ${ }^{8}$ (1996) states that children aged 
4 to 5 years are the most likely to suffer trauma. However, the current literature is unanimous in that trauma occurs as a result of psychomotor underdevelopment and poor motor skills, which do not allow the child to perform precise and safe movements. ${ }^{9,10,11}$

The maxillary central incisors followed by maxillary lateral incisors have been reported as the most frequent injured teeth in the primary dentition. ${ }^{4,12,13}$ Because of the resilient bone surrounding the primary teeth, the majority of injuries are tooth luxations. ${ }^{2,13,14}$

The assessment of traumas in the primary dentition seems to be very relevant not only because of the presence of sequelae in the present dentition, but also because it allows the identification of possible development alterations in the permanent dentition. Unfortunately, people in general are not well informed about the risks of trauma in the deciduous and permanent dentitions and what can be done to avoid them. ${ }^{2}$

There are several studies in the literature that evaluate the prevalence of dental traumatism in the primary and permanent dentitions, $, 2,6,12,15,16$ although just a few of them present the epidemiology of primary teeth sequelae in face of these traumas. ${ }^{17,18}$

In this context, the present study was conducted to assess the prevalence of traumatic injuries in children aged 0-6 years and the resulting sequelae in the primary dentition. The children were attended by the Dental Trauma Project, Federal University of Rio de Janeiro (UFRJ), Brazil.

\section{Method}

An observational survey was carried out among preschool children aged 0 to 6 years seen in the period from 2004 to 2006 at the dental trauma clinic, Federal University of Rio de Janeiro, Brazil. The study was approved by the local ethics committee, and was accomplished at the Dental Trauma Clinic, a dentoalveolar traumatism reference center that provides access, care and follow-up for 0-12 year old children.

The sample comprised a total of 111 preschool children, and 201 (n) deciduous teeth were used in the analysis. The children could have more than one tooth affected by trauma.

The following information pertaining to the child and to the trauma were collected from the dental record: gender and age at the time of trauma, etiology (fall from own height, accidents, collision and others), teeth involved, type of traumatic injuries (fractures and luxations), time elapsed between the trauma and seeking care, presence and kind of clinical and radiographic sequelae observed at the first visit.

Traumatic injuries to the maxillary and mandibular primary teeth were recorded according to the method described by Andreasen, Andreasen ${ }^{19}$ (1994) as follows:

\section{Fractures}

- Fracture of the crown: enamel only, enamel and dentin with or without pulp exposure.

- Fracture of the crown with pulp exposure: enamel and dentin with pulp exposure.

- Crown-root fracture: fracture involves enamel, dentin and root structure; the pulp may or may not be exposed.

- Root fracture: the coronal fragment is mobile and may be displaced.

- Alveolar fracture: the fracture involves the alveolar bone.

\section{Luxations}

- Concussion: the tooth is tender to touch without increased mobility or sulcular bleeding.

- Subluxation: increased dental mobility without displacement, taking into account the mobility of the affected tooth as compared to the physiological mobility of the homologous tooth.

- Lateral luxation: tooth displacement to a nonaxial direction.

- Intrusive luxation: tooth displacement into the alveolus.

- Extrusive luxation: tooth displacement out of the alveolus.

- Avulsion: tooth prematurely lost if compared with the homologous tooth.

The kind of clinical and radiographic sequelae 
observed at the first visit was recorded according to the method described by Andreasen, Andreasen ${ }^{19}$ (1994) as follows, except for avulsed teeth:

\section{Clinical sequelae}

- Absence of clinical signs.

- Crown discoloration: hange in the crown coloration; tooth presenting darker tones when compared to the adjacent teeth.

- Abscess: infection caused by bacteria or parasites with the production of pus.

- Edema: accumulation of an excessive amount of watery fluid in tissues or excess tissue mass.

- Fistula

\section{Radiographic sequelae}

- Absence of radiographic evidence.

- Periapical lesion: area of apex rarefaction without root resorption.

- Internal resorption: tooth decay that initiates in the internal dentin walls, pulp chamber and root canal.

- External resorption: progressive root structure loss; the tooth root is dissolved away from the root surface inward, toward the pulp.

- Pulp calcification: the pulp chamber and root canal are obliterated due to progressive hard tissue deposition.

- Substitutive resorption: progressive replacement of dental tissues by bone tissues.

- Increased periodontal ligament space.

Time elapsed between the time of traumatic injury and seeking care time was considered as:

- Immediate: less than 24 hours elapsed from the time of dental trauma.

- Not immediate: more than 24 hours elapsed from the time of dental trauma.

Quantitative analysis of the collected data was performed by using a statistical program (version 11.0, SPSS Inc., Chicago, IL, USA). The relative frequency $(\%)$ of all variables studied was obtained and the relation between them was assessed by the nonparametric Chi-square test $(\mathrm{p}<0.05)$.

\section{Results}

The final sample consisted of 111 patients $(56.7 \%$ boys; $43.3 \%$ girls). For the final analysis, a total of 201 traumatized primary teeth were included in the study. The great majority was present in the maxillary arch $(97.6 \%)$, being the central incisors $(84.7 \%)$ the most affected teeth, followed by the lateral incisors $(13.3 \%)$. The majority of the traumas occurred from $0-3$ years of age $(73.8 \%)$. Children aged 2 years were the most affected $(29.9 \%)$.

The most common trauma cause related by the children's parents or guardians was fall from the child's own height $(63.0 \%)$, followed by accidents $(16.3 \%)$. When relating the cause to the child's gender and age, a higher prevalence was observed in boys $(\mathrm{p}=0.04)$ and in the age group from $0-3$ years $(\mathrm{p}=0.05)$.

The most prevalent type of trauma observed was luxation $(85.0 \%)$; lateral luxation was the most frequent injury $(33.4 \%)$ present, followed by concussion $(21.0 \%)$. In this study, a low frequency of traumatisms resulted in tooth fracture $(15.0 \%)$. Most fractures did not involve the pulp (56.7\%) (Table 1), while fractures of the alveolar process, fractures of the root and crown-root fractures were not listed.

Of the 201 teeth included in the final analysis, $15(7.5 \%)$ suffered avulsion and had to be excluded, leaving a total of 186 teeth. Of these, 133 (71.5\%) presented no clinical signs of sequelae. Clinical sequelae were present in $53(28.5 \%)$ teeth; coronal

Table 1 - Prevalence of dentoalveolar traumatisms.

\begin{tabular}{l|c|c}
\hline \multicolumn{1}{c|}{ Luxations } & $\mathrm{N}$ & $\%$ \\
\hline Lateral luxation & 57 & 33.4 \\
\hline Concussion & 36 & 21.0 \\
\hline Intrusive luxation & 24 & 14.0 \\
\hline Subluxation & 24 & 14.0 \\
\hline Extrusive luxation & 15 & 8.8 \\
\hline Avulsion & 15 & 8.8 \\
\hline Total & 171 & 100 \\
\hline Cractures & $\mathrm{N}$ & $\%$ \\
\hline Crown fracture with pulp exposure & 13 & 56.7 \\
\hline Total & 30 & 100 \\
\hline
\end{tabular}


Table 2 - Prevalence of dentoalveolar clinical sequelae.

\begin{tabular}{l|c|c}
\hline \multicolumn{1}{c|}{ Clinical sequelae } & N & $\%$ \\
\hline Coronal discoloration & 33 & 17.7 \\
\hline Abscess & 20 & 10.8 \\
\hline Absence of clinical signs & 133 & 71.5 \\
\hline Total & 186 & 100 \\
\hline
\end{tabular}

discoloration $(17.7 \%)$ was the most prevalent alteration followed by abscess (10.8\%) (Table 2). Edema and fistula were absent.

As regards radiographic sequelae, except for the avulsed teeth, 109 (58.6\%) presented no sequelae and $77(41.4 \%)$ presented at least one sequela. The most frequent sequela was external resorption $(18.3 \%)$ followed by periapical lesion $(12.4 \%)$ (Table 3). Increased periodontal ligament space and substitutive resorption were not observed.

When assessing the influence of gender on clinical and radiographic sequelae, there was no statistically significant difference (respectively $\mathrm{p}=0.54$ and $\mathrm{p}=0.55)$. Age seemed not to have any influence on radiographic sequelae $(\mathrm{p}=0.41)$; however, clinical sequelae were more evident in children aged 0-3 years $(\mathrm{p}=0.03)$.

As regards the time at which treatment was sought, it was observed that most of the sample $(78.6 \%)$ were classified as not immediate (more than $24 \mathrm{~h}$ from the time of dental trauma).

\section{Discussion}

Considering the gender and the prevalence of traumatisms in the primary dentition, boys were more affected by trauma events than girls in the present study. Although this difference was not as marked as in other studies, ${ }^{20}$ the trend of the result appears to reflect the more agitated nature of boys in comparison with girls.

The 0-3 years age group was the most frequently affected by traumatisms. This finding is in agreement with those of the literature specifically related to the subject. As it is the time when the child acquires independence and starts to explore its environment, the increase in injuries is natural. ${ }^{10}$

In agreement with the findings of other authors, it was found that a fall from the child's own height,
Table 3 - Prevalence of dentoalveolar radiographic sequelae.

\begin{tabular}{l|r|c}
\hline \multicolumn{1}{c|}{ Radiographic sequelae } & N & $\%$ \\
\hline External resorption & 34 & 18.3 \\
\hline Periapical lesion & 23 & 12.4 \\
\hline Root fracture & 9 & 4.8 \\
\hline Alveolar fracture & 4 & 2.2 \\
\hline Internal resorption & 4 & 2.2 \\
\hline Pulp calcification & 3 & 1.6 \\
\hline Absence of radiographic evidence & 109 & 58.6 \\
\hline Total & 186 & 100 \\
\hline
\end{tabular}

followed by other falls, was the most frequent etiologic factor for the occurrence of traumatisms. ${ }^{20}$

As related in other studies,,$^{2,4,9,20}$ the maxillary arch and the central maxillary incisors were the most affected arch and teeth.

According to some authors, ${ }^{2,13,14}$ the most frequent type of trauma in the primary dentition is that affecting the supporting tissues (luxations). This was confirmed in the present study, in which a low frequency of traumatisms resulting in tooth fracture $(15.0 \%)$ was observed. The mentioned datum could be explained by the bone immaturity of children in the above mentioned group, or another decisive mechanism which may be involved in this process, a factor that should be the object of future analyses.

According to Soxman et al. ${ }^{21}$ (1984), primary tooth discoloration is a common post-traumatism episode. According to Holan, Fuks ${ }^{22}$ (1996), this results from pulp hemorrhage, and coloring can vary from yellow to pink, pink to gray and gray to black. Tooth discoloration was also important in the spectrum of clinical sequelae observed in the present study. When the entire spectrum of clinical sequelae was analyzed, it was observed that all sequelae were more prevalent in the age group from 0 to 3 years, when compared with the age group from 4 to 6 years.

Dental mobility was not observed during the first visit because its presence immediately after the trauma would be considered luxation, i.e., it would represent a feature of the trauma and not a sequela resulting from it. We therefore suggest that in future studies this criterion be used for assessing this se- 
quela, i.e., that mobility be assessed only in followup visits.

In the present research, the most prevalent type of sequela was radiographic (41.4\%). This finding can be explained by the greater number of patients who seek dental care due to a non-immediate complaint (more than 24 hours after the trauma) and because radiographic sequelae take more time to become apparent than do clinical sequelae. Additionally, clinical recovery may occur while no radiographic repair is evident. When analyzing the radiographic sequelae observed, it was found that pathological inflammatory resorption was the most frequent alteration, in agreement with other published studies on the subject. ${ }^{18}$

With regard to seeking treatment, most of the sample sought care at a not immediate time (more than 24 hours after the trauma), which could be a critical factor in determining a post-traumatism prognosis. A possible factor involved in the delay of initial care is the perception of the severity of the event by the children's parents or guardians. The absence of bleeding, apparent mobility, and pain, among other broader clinical factors, usually leads parents not to seek immediate dental treatment, which facilitates consolidation and aggravation of subclinical lesions, which in turn may eventually lead to a worst prognosis.

The importance of the time elapsed between the trauma event and initial treatment for the prognosis of the trauma should be emphasized in educational practice of primary prevention. Parents should be aware of the importance of seeking immediate treatment and of a periodic follow-up by the dentist with the objective of limiting the damage to the deciduous and permanent dentitions.

\section{References}

1. Flores MT. Traumatic injuries in the primary dentition. Dent Traumatol. 2002;18(6):287-98.

2. Cardoso M, de Carvalho Rocha MJ. Traumatized primary teeth in children assisted at the Federal University of Santa Catarina, Brazil. Dent Traumatol. 2002;18(3):129-33.

3. Kramer PF, Zembruski C, Ferreira SH, Feldens CA. Traumatic dental injuries in Brazilian preschool children. Dent Traumatol. 2003;19(6):299-303.
Knowledge of the type of traumatic lesion, its location, clinical and radiographic extent, and post trauma sequelae is extremely important to determine the prognosis for the primary and permanent dentitions.

It is therefore suggested that further studies be conducted over a longer period of time, involving a follow-up of the development and course of sequelae to assess the possible importance of the time elapsed after the trauma in their severity. Such studies should evaluate the sequelae resulting from dental trauma both in the primary and permanent dentitions, but with special emphasis on the former since it is not widely described in the literature.

\section{Conclusion}

After evaluating the factors that most frequently contribute to dental traumatisms in the primary dentition, it could be concluded that traumatisms in primary teeth were more prevalent in boys, and in the 0-3 years age group. Luxation was the most frequent traumatic lesion, and coronal discoloration and external resorption were the most prevalent sequelae.

\section{Acknowledgements}

The authors would like to thank Professor Ronnir Raggio Luiz (IESC/ UFRJ) for the statistical analysis support, and DAB/SAS/MS (Department of Primary Care / Secretary of Health Care / Ministry of Health), DECIT/SCTIE/MS (Department of Science and Technology / Secretary of Science, Technology and Strategic Resources / Ministry of Health) - CNPq (The National Council for Scientific and Technological Development) for the financial support.
4. Skaare AS, Jacobsen I. Primary tooth injuries in Norwegian children (1-8 years). Dent Traumatol. 2005;21(6):315-9.

5. Granville-Garcia AF, de Menezes VA, de Lira PIC. Dental trauma and associated factors in Brazilian preschoolers. Dent Traumatol. 2006;22(6):318-22.

6. Beltrão EM, Cavalcanti AL, Albuquerque SS, Duarte RC. Prevalence of dental trauma children aged 1-3 years in João Pessoa (Brazil). Eur Arch Paediatr Dent. 2007;8(3):141-3. 
7. Cardoso M, Rocha MJC. Federal University of Santa Catarina follow-up management routine for traumatized primary teeth - part 1. Dent Traumatol. 2004;20(6):307-13.

8. Osuji OO. Traumatised primary teeth in Nigerian children attending University Hospital: the consequences of delays in seeking treatment. Int Dent J. 1996;46(3):165-70.

9. Mestrinho HD, Bezerra ACB, Carvalho JC. Traumatic dental injuries in Brazilian pre-school children. Braz Dent J. 1998;9(2):101-4.

10. Borum MK, Andreasen JO. Therapeutic and economic implications of traumatic dental injuries in Denmark: an estimate based on 7549 patients treated at a major trauma center. Int J Paediatr Dent. 2001;11(4):249-58.

11. Pugliesi DM, Cunha RF, Delbem AC, Sundefeld ML. Influence of the type of dental trauma on the pulp vitality and the time elapsed until treatment: a study in patients aged 0-3 years. Dent Traumatol. 2004;20(3):139-42.

12. Oliveira LB, Marcenes W, Ardenghi TM, Sheiham A, Bönecker M. Traumatic dental injuries and associated factors among Brazilian preschool children. Dent Traumatol. 2007;23(2):7681.

13. Bastone EB, Freer TJ, Monamara JR. Epidemiology of dental trauma: a review of the literature. Aust Dent J. 2000;45(1):29.

14. Saroglu I, Sonmez H. The prevalence of traumatic injuries treated in the pedodontic clinic of Ankara University, Turkey during 18 months. Dent Traumatol. 2002;18(6):299-303.
15. Nicolau B, Marcenes W, Sheiham A. The relationship between traumatic dental injuries and adolescents' development along the life course. Community Dent Oral Epidemiol. 2003;31(4):306-13.

16. Cortes MI, Marcenes W, Sheiham A. Prevalence and correlates of traumatic injuries to the permanent teeth of schoolchildren aged 9-14 years in Belo Horizonte, Brazil. Dent Traumatol. 2001;17(1):22-6.

17. Kenwood M, Seow WK. Sequelae of trauma to the primary dentition. J Pedod. 1989;13(3):230-8.

18. Borum MK, Andreasen J. Sequelae of trauma to primary maxillary incisiors. I. Complications in the Primary Dentition. Endod Dent Traumatol. 1998;14(1):31-44.

19. Andreasen JO, Andreasen FM. Textbook and color atlas of traumatic injuries to the teeth. $3^{\text {rd }}$ ed. Copenhagen: Munksgaard; 1994. $771 \mathrm{p}$.

20. Bijella MFTB, Yared FNFG, Bijella VT, Lopes ES. Occurrence of primary incisor traumatism in Brazilian children: a houseby-house survey. ASDC J Dent Child. 1990;57(6):424-7.

21. Soxman J, Nazif M, Bouquot J. Pulpal pathology in relation to discoloration of primary anterior teeth. J Dent Child. 1984;51(4):282-4.

22. Holan G, Fuks A. The diagnostic value of coronal dark-gray discoloration in the primary teeth following traumatic injuries. Pediatr Dent. 1996;18(3):224-7. 